\title{
Toward an Understanding of Flow in Video Games
}

\author{
BEN COWLEY, DARRYL CHARLES, MICHAELA BLACK, \\ AND RAY HICKEY \\ University of Ulster, Coleraine, Northern Ireland, U.K.
}

\begin{abstract}
In the domain of computer games, research into the interaction between player and game has centred on 'enjoyment', often drawing in particular on optimal experience research and Csikszentmihalyi's 'Flow theory'. Flow is a well-established construct for examining experience in any setting and its application to game-play is intuitive. Nevertheless, it's not immediately obvious how to translate between the flow construct and an operative description of game-play. Previous research has attempted this translation through analogy. In this article we propose a practical, integrated approach for analysis of the mechanics and aesthetics of game-play, which helps develop deeper insights into the capacity for flow within games.
\end{abstract}

The relationship between player and game, characterized by learning and enjoyment, is central to our analysis. We begin by framing that relationship within Cowley's user-system-experience (USE) model, and expand this into an information systems framework, which enables a practical mapping of flow onto game-play. We believe this approach enhances our understanding of a player's interaction with a game and provides useful insights for games' researchers seeking to devise mechanisms to adapt game-play to individual players.

Categories and Subject Descriptors: H.1.1 [Models and Principles]: Systems and Information Theory Information theory; H.5.2 [Information Interfaces and Presentation]: User Interfaces - User-centred design; Theory and methods; J.7 [Computer Applications]: Computers in Other Systems - Consumer products

General Terms: Design, Human Factors, Performance, Theory

Additional Key Words and Phrases: Games, aesthetics, engagement, flow, information, relational structure

ACM Reference Format:

Cowley, B., Charles, D. Black, M., and Hickey, R. 2008. Toward an understanding of flow in video games. ACM Comput. Entertain. 6, 2, Article 20 (July 2008), 27 Pages. DOI = 10.1145/1371216.1371223 http://doi.acm.org/10.1145/1371216.1371223

\section{INTRODUCTION}

"The destiny of games is to become boring...Fun is a process and routine is its destination." [Koster 2005a]

In current research that focuses on modern commercial computer and video games (hereinafter called games), there is a strong emphasis on the development of novel player-centered technologies [Hallam and Yannakakis 2007; Schaeffer and Mateas 2007]. One fundamental aspect of this research involves uncovering the 'fun process'; that is, discovering how interaction with a game system can lead to pleasurable and/or rewarding experiences for the player. Understanding this process would be required in order to (for example) make games that adapt to enhance the play experience for individual players.

\footnotetext{
Authors' address: School of Computing, University of Ulster, Cromore Road, Coleraine, BT52 1SA, Northern Ireland; Contact author: Ben Cowley; email: \{cowley-b, dk.charles, mm.black, rj.hickey\}@ulster.ac.uk

Permission to make digital or hard copies of part or all of this work for personal or classroom use is granted without fee provided that the copies are not made or distributed for profit or commercial advantage, the copyright notice, the title of the publication, and its date of appear, and notice is given that copying is by permission of the ACM, Inc. To copy otherwise, to republish, to post on servers, or to redistribute to lists, requires prior specific permission and/or a fee. Permission may be requested from the Publications Dept., ACM, Inc., 2 Penn Plaza, New York, NY 11201-0701, USA, fax: +1 (212) 869-0481, permissions@acm.org (C)2008 ACM 1544-3574/2008/07-ART20 \$5.00 DOI = 10.1145/1371216.1371223

http://doi.acm.org/10.1145/1371216.1371223
} 
This play experience develops out of the relationship between player and game, and in this article we discuss how a deeper understanding of the application of flow theory to games can improve our description of the relationship between a player and the complex game system [McKenzie and James 2004].

As a framework for our analysis we adapt the person-artefact-task (PAT) model [Finneran and Zhang 2003] - a relational schema based around task performance. This is a propositional model which operationalises experience-description constructs in the context of a computer-mediated experience (CME). However PAT, as with most user centred design (UCD) for CMEs, is focused largely on productivity software, and as pointed out in Charles et al [2005], there is an important difference between usability and playability. Entertainment outweighs productivity as the primary motivating factor behind game-play. Thus, while attempting to describe the relational elements that create a game-play experience, the authors developed the user-system-experience (USE) model [Cowley et al 2006a] (see Figure 1). This is a propositional model aimed at describing a player-game system, inspired by the PAT model. The primary function of USE is to describe the player-game relationship, which it does in terms of constructs from the literature on personality types [Batemen and Boon 2005], optimal psychology or Flow theory [Csikszentmihalyi 1975b], and human-computer interaction (HCI) [Steuer 1995] (see Sections 2.2 and 2.3). In this article, our updated model also serves to set the scene for a deeper look at the interaction of user and system, and the experience of flow in games.

To get closer to a more operative description of game-player interaction, we attempt to redefine the constructs in our USE schema in terms of a common framework that is derived from previous work on information systems [Rauterberg 1995]. This framework suggests there is a remarkable functional similarity between game-play and flow (Section 2.3). Before moving on to detailed analysis, we undertake a detailed background review of related material. Thus in Sections 2.1 and 2.2 we describe some fundamental concepts on game structure and player modelling, to show how games and players can be formally described; and in Section 2.3 we address how to study the subjective enjoyment of the player. In Section 3 we examine the relationship between playing games and optimal experience and review literature that deals with this relationship. Finally, in Section 4 we use the paradigm of games as information systems to investigate how they might provide

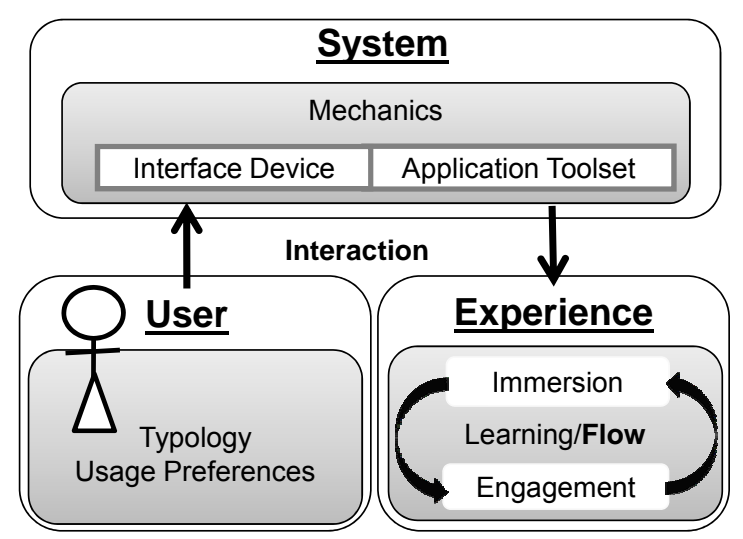

Fig. 1. User-system-experience (USE) model - adapted from Cowley et al. [2006a]. 
optimal experience. Section 5 gives our conclusions and the possible further applications of our work.

\section{UNDERSTANDING THE GAME AND THE PLAYER - THE USE MODEL}

"It is absolutely vital that we start to build a vocabulary that allows us to examine, with some degree of precision, how games evoke emotional-intellectual responses in players". Warren Spector in Salen and Zimmerman [2003]

The USE model is composed of three parts. For the duration of the play session a user is defined by personal information and/or logged play data, which can be modelled with given typological constructs and/or modelling constructs respectively (see Section 2.2). Typologies apply universally across games and players, but modelling methods are gamespecific, and thus depend on the system. A computer gaming system may contain one-tomany parts, with much variation in their types, corresponding to game code and entities. Emergent mechanics ${ }^{1}$ of game-play depend on these parts, and give rise to the type of experience a player will have. A computer gaming experience is dependent on the properties of the other segments of the USE model. Experience is described by its own constructs (see Section 2.3) that model the interactions between player and system. This USE schematic shows the inter-relationships among user, system, and experience framing the current discussion on how players interact with games and how they can obtain an optimal experience in-game.

\subsection{Game Structure - The System Segment}

In order to understand the structure of a game, we need a way to represent it as a formal or semi-formal information system, and to relate it to similarly systematic representations of the player and his or her experience. Hence we will expand upon our system segment here. This segment of the USE model indicates what may be involved in the hardwareand software-based aspects of the CME. From a user-centred point of view, this breaks down into input and output. That is, input is delivered to interface devices (controllers and the like) and output comes via a virtual world or application toolset (the in-game tools of player agency; which encapsulates the structural and operational elements that a person uses to play a game; we will examine such elements below).

There are several definitions of computer games and gaming in the literature, from a variety of sources such as ludologists [Wolf and Perron 2003], game designers [Crawford 2002], and game studies researchers [Salen and Zimmerman 2003]. For convenience, we offer our own here: game-play occurs as a rule-bound, reactive, emergent process of action sequences belonging to one or more players. Essentially, the rules governing the exploration of the game's possibility space by this process are the game's mechanics; mechanics heavily influence a player's experience [Salen and Zimmerman 2006].

To see this, consider the board game Go [Wilcox 1985]. Players of Go must alternately place black or white stones on a grid, and once placed, stones are not moved forthwith. This game has a remarkably simple set of rules, and very few aesthetic embellishments - and yet it is one of the most enduring board games, still widely played;

\footnotetext{
${ }^{1}$ Mechanics being "the various actions, behaviours and control mechanisms afforded to the player" [Hunicke et al. 2004]. This is also the way in which a player is given agency, which is the provision of capability for a player to act meaningfully and with visible effect in a game - this is a core requisite of any game [Murray 1997].
} 
the depth and complexity of the game providing endless enjoyment without the "colour" [Costikyan 1994] of Monopoly and the like. Sudoku might be considered similar:

Board games are a simple example of the emergence of great complexity from simple rules or laws...Chess and Go have enough emergent properties that they continue to intrigue us and offer new discoveries after centuries of study. [Holland 1998]

In this way mechanics give rise to the dynamics ${ }^{2}$ of player/game interaction, and understanding them is correspondingly important. To do this, we consider a rule-defined game as a formal system. Any system based on rules can be expressed as a formal system [Holland 1998], which means it will have a formal logic that can be considered roughly analogous to game mechanics. Specifying the formal system allows the mechanics to be determined, thus moving a step closer to uncovering the player/game interaction relationship.

Unfortunately, usefully specifying a formal system requires an agreed structural specification language, which does not exist yet in modern computer game design. This lack of standardization compounds the fact that it is very hard to derive the abstract formal specification of game structure by naively examining the game engine code. Without understanding the game's formal structure, the only way to understand how the player sees the game and how the interaction between game and player works is by extensive post-development testing. This may be necessary anyway, but it has many of the flaws of reverse-engineering, such as subjectivity, and its unavailability to the games' researcher. Thus we would suggest that when analyzing games it is important to use some structural/operational specification language to help show the space of possibilities in emergent game-play. Since our analytical approach considers games as information systems, we require a process model that captures the player's agency and the relational schema of interaction. Such a model needs to describe how the fundamental building blocks of the game interoperate and pass information around. We describe some existing approaches below in order to illustrate how one can formally describe game-play and to support our discussions in Section 4.

Games are delimited by rules that structure game-play by being binding and absolute (although freely accepted) [Parlett 1999; Suits 1990; Avedon and Sutton-Smith 1971; Abt 1970]. Defining the nature of rules and identifying their structure is important in formal specification. Salen and Zimmerman's [2003] comprehensive study of play and games provides a most useful taxonomy of the types of rules that govern play, allowing us to talk about how games work at different levels of formality.

(1) Constituative ${ }^{3}$ rules are the abstract formal structures that create the mechanics of game-play and underlie how the operative rules work, in that they specify sets of logical relationships that are invariant and well-formed.

(2) Operative rules define how the player "operates" the game in terms that are situated, informal, and designed for nonspecialist consumption. They describe all interactive elements that have an effect on game-play.

(3) Implicit rules are largely social and informal, and govern behavior around play. They are usually brought to the game by the players, and include

\footnotetext{
${ }^{2}$ Dynamics is "the run-time behaviour of mechanics acting on player inputs, and [system] outputs" [Hunicke et al. 2004]; i.e., most levels of interaction [Salen/ Zimmerman 2003].

${ }^{3}$ Constituative: this word is not dictionary-supported, although it is very close in spelling and meaning to constitutive. However as it is their definition, we follow their neologism.
} 
constraints such as not using code modifications (that other players can't access) to confer selfish advantages in a multiplayer game - that is, cheating [Kucklick 2004].

As the simulation of virtual environments in games increases in its fidelity to real environments, it may become harder to map a computer games' Constituative rules to a formal model, as some formal rules of the game (e.g. character jumping times) may get encapsulated by the implicit rules of the simulation (e.g. gravity). Still, although it may be nontrivial, distinguishing among these rule types is an important first step in defining the game system with which the player will interact and from which will potentially derive her/his optimal experience.

Several game designers have written on the subject of game system specification in more or less formal ways [Bateman 2006; Church 1999; Cousins 2004; Koster 2005b].This formative work by the game design community is ongoing, and there is as yet no clear consensus on a common framework. One starting point is to use grammars; intuition would suggest a formal generative grammar, although attempts have also been made in using an analytical grammar instead [Chomsky 1956]. The main point is to formulate games as sets of verbs and nouns. We can express this idea simply, as follows:

1. The human player

- $\quad$ [Noun] A player-controlled avatar(s) - the focus of player agency

- $\quad$ [Verb] The player's action set in the game

2. Nonplayer characters (NPC)

- [Noun] Avatar

- $\quad$ [Verb] NPC behavior - i.e., agent A.I.

3. The game environment

- $\quad$ [Noun] Environmental models

- $\quad$ [Verb] Typically, mechanical action - e.g., windmills, lifts.

This approach increases in complexity quite quickly, as we identify a relational schema between nouns - that is, which scope do their verbs act on (distinguishing local and global agency) and to which nouns do they apply (assigning scope).

One further distinction we must make is a basic unit for the action of verbs - that is, the unit size of the most basic possible meaningful game action. Since the duration of the action depends entirely on the context and game design (Figure 3), "unit size" must be distinguished in some other way. Cook [2006], Heaton [2006[, and Cousins [2005], among others, have defined models for this - all of which work on a fairly similar atomic game model, describing game loops as an output/input cycle - so an atom is the shortest possible loop. Since it must include both output and input, a loop will have inherent meaning within game- play, approximately similar to a challenge/response exchange on the bidirectional interaction channel between game and player.

Cousins' [2005] loops are hierarchical and derived from empirical measurements; that is, the topmost loop in the hierarchy is the game itself (corresponding to Huizinga's [1949] Magic Circle); the lowest loop is the base unit of time for a player to perform an action in a standard game. For instance, by timing the player avatar's jumps in a range of contemporary action games, Cousins [2005] (Figure 3) found a majority cluster (with a very low standard deviation) containing all the most successful games of those measured. These games were very diverse in their structures and origins (i.e., their developers). This 


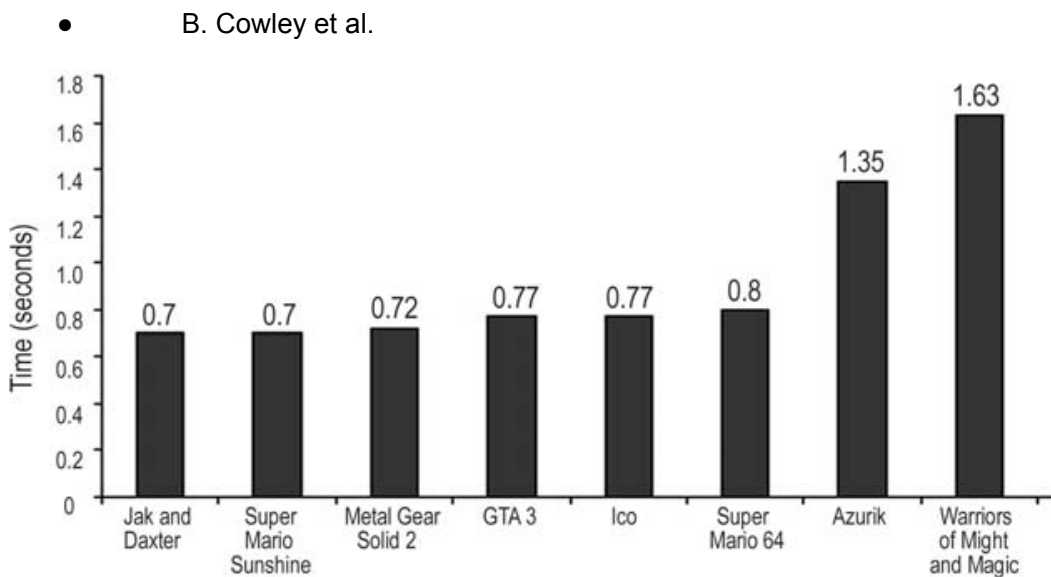

Fig. 3. Jumping times in 3rd person action games - adapted from Cousins [2005].

suggests (though doesn't prove) that this cluster represents an objective invariant "sweet spot" (an optimal value) for the jumping action in this game type.

Subatomic "particles" in the loop are the nouns of the game in a state that is invariant during the atomic loop - player, environment, opponent, weapons. Their interaction is governed by their verbs. So an atomic loop corresponds to a game state - which is appropriate, since games are often built on state machine logic.

Koster's [2005b] is another promising approach, which gives the details of the algorithm that provides the possible space for the game. In this specification method, atoms equate to a core verb in the game-play (such as shoot, run, or jump). Verbs stack in a hierarchy and segue - the player forms larger verbs by combining smaller ones - and the hierarchy ends when a verb obtains certainty of outcome. The notation includes rules or guidelines such as "atoms must have a failure state link," which corresponds to game actions always having associated risks/meanings. However, this method abstracts the effects of time from the play experience.

Combining both methods above would explain both the player agency (in terms of verbs acting on nouns), and the practical experience (in terms of timing). In order to do this, we would need a dynamic system specification method such as Petri nets [Petri 1962; Bura 2006] to specify an isomorphism from atomic transitions between places to the actions permitted by the operational rules of the game.

Current models are, on the whole, overly simple and incomplete. Yet they point to a method by which games could be specified to enable measurement of complex interactive processes, and thus the comparison of operative structures in game-play. The verbs, and perhaps timings, in the specification would offer a cogent picture of the type of experience that the mechanics of the game would create. (Aesthetic elements might alter the superficial experience; but this is outside the scope of our discussion.) In order to make use of this picture we must know what experience the player prefers. So we must also consider the player beyond the game, as a persistent entity, and try using methods such as typologies to look at the player's persistent attributes.

\subsection{Player Modeling - The User Segment}

To analyze how games can produce flow, we need to specify the player as well as the game and the experience. Player variability is little researched to date, which is surprising given that each type of player alters the requirements for an experience to deliver flow. 
Player modeling and adaptive technologies may be used alongside existing approaches to facilitate improved player-centered game design in order to provide a more appropriate level of challenge, smooth the learning curve, and enhance the game-play experience for individual players regardless of gender, age, and experience. [Charles et al.l 2005]

The user segment (of the USE model) holds a task-relevant set of profile data types, such as can be captured prior to primary system interaction - that is, prior to game-play. Such profile data would be used to identify the player within a typological construct (see below), and is usually static during play. To complement typological data capture, realtime player modeling is also used. Player modeling is a technique for inferring the player's higher-order attributes by using the large quantity of primitive-type data available from the game engine, involves recording a set of semantically-relevant information on the player, and using some classification algorithm to describe them for other processes. Semantically-relevant information would include IO stream data that shows, for example: player reflex speed; player shooting accuracy; positioning with reference to opponents; average number of level replays; and so on. Raw data can be structured (i.e., building the player) around axiomatic knowledge of the natural structure of player-game interaction; see Section 2.1.

Recent work [Houlette 2004] has looked at methods to automatically model players based on factorization of their game-play attributes, for example in an FPS, recording factors (such as ratio of shots-fired to shots-on-target) that comprise the player's accuracy attribute (Figure 4). This algorithm can be directed, as in Houlette [2004], or be selforganizing, as in Charles et al. [2005]. The former may be more computationally efficient but is less generic and relies on expert input to define factors and attributes. The latter method would use unsupervised neural networks to build correlations from raw data sets, and so create factors that are not predefined by algorithm designers but arise naturally from play - however, it may not be usable in real-time. There are other promising modeling techniques such as descriptive decision theory [Cowley et al. 2006b], which offers a data-driven approach with some degree of expert supervision.

However, these simple player models are not enough to fully describe the user's experience in playing a game - because we also need to ask: What type of gaming experience do the players enjoy? What level of challenge do they want to face? Do they prefer an edge-of-the-seat experience, barely in their control, or to have a comfortable control buffer; or something in between? For these questions, we need more information about the players, so in addition to looking at types of games [Caillois 1962], we consider it necessary to study the types of players [Bartle 1996] (and below), and the psychology of enjoyment or optimal experience [Csikszentmihalyi 1975a; 1975b; 1990] (see Section 2.3).

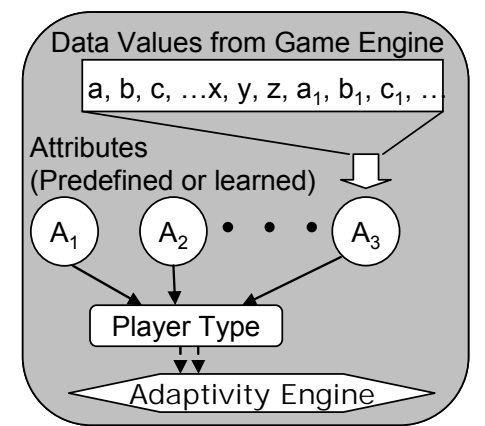

Fig. 4. A schematic of in-game modeling. 
Essentially, the best way to get information about the players is to ask them directly, which is not feasible in-game as it breaks immersion, ${ }^{4}$ and so must be done via pregame profiling. This method has been used for many years, in the simple form of levels of difficulty. Players are commonly offered a choice of three or more distinct levels of difficulty through which advancement is preset and linear. There are several problems inherent in this:

the game views player advancement as linear and so becomes progressively more complex (e.g., difficult) as [it] is traversed. Unfortunately this view is that of an "ideal" user and so some players may feel somewhat discontented when they advance in a manner that is counter to the “ideal’ advancement model. [Gilleade and Dix 2004]

Spronck and van den Herik [2005] also offered cogent arguments against static difficulty levels. In addition to difficulty levels, a more satisfactory solution would use typological constructs to discover play preferences that go beyond "easy," "medium," and "hard".

Typologies are an important tool for user modeling or user centered design, since they allow classification of individuals that is reasonably accurate (low false positives), if not very precise (broad classes). A basic tenet is that individuals almost always fall into more than one class. Temperament theory describes one's instinctive preference for modes of thought and behavior, across four combined indices which are two-valued, giving $2^{\wedge} 4=$ 16 separate types. It is derived from very old psychological concepts, but many modern typologies, each with their own testing tools, are based thereon. Two of the more prominent are MBTI [Ludford and Terveen 2003] and the Keirsey temperament sorter [Kiersey 1984]. Demographic game design (DGD, Figure 5) [Bateman and Boon 2005] has taken both these constructs as its basis in describing player types and their associated game play-preferences. As an example typology, DGD has the disadvantage of being based on small numbers of survey respondents; but also the advantage that its types correlate with those of MBTI, which has the largest test-base of all typological studies.
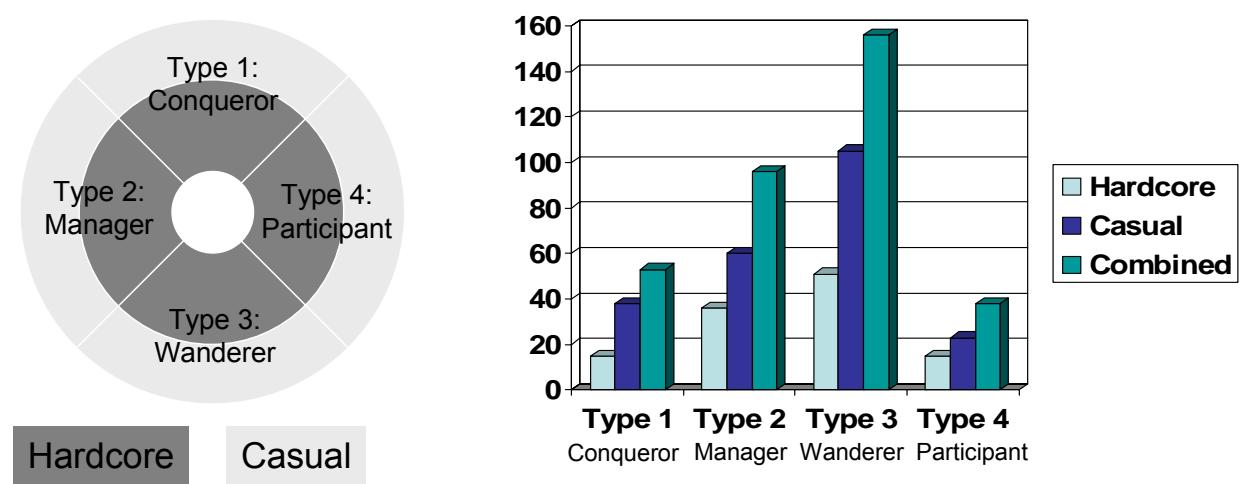

Fig. 5. DGD types and distribution across survey respondents (in actual numbers of respondents); adapted from Bateman and Boon [2005].

\footnotetext{
${ }^{4}$ Immersion can be defined as "being absorbed within...a familiar schema" [Douglas and Hargadon 2000] where a schema is cohesive descriptive information presented via media.
} 
The DGD typology gives us four types. Gamers will belong to each of the types to a greater or lesser degree - type membership is non-exclusive. The types can be briefly described as follows:

- Conqueror: Competitive, win-at-all-costs. Players of this type are goal-oriented and enjoy feeling dominant in the game or in social circles set around the game.

- Manager: Logistical, plays to develop mastery. Such players are processoriented and will replay completed games if they can use their newfound mastery to unearth novelty at deeper levels of detail.

- Wanderer: Desires new and fun experiences. Less challenge-oriented than the above types, these players primarily seek constant, undemanding. and enjoyment.

- Participant: Enjoys social (living-room) play, or involvement in an alternate world.

There is a further cross-type split between dedicated or hardcore players, and recreational or casual players. Casual players may or may not play as much as the hardcore players, as commonly conceived, do. The technical distinction is that casual players choose not to spend as much time "meta-gaming," that is, in learning, talking, and creating communities with others around the subject of games; they are not as gameliterate

Another approach to distinguish players is to identify the motivational attitude prevalent in the players of each game type. This is how Caillois [1962] developed his model of game types - four different styles or forms of playing - agôn (competition), alea (games of chance), mimicry (role-playing), and ilinx (vertiginous immersion). He also identified a continuum of form. from paidia (unstructured play as that of young animals [Groos 1898]) to ludus (rule-bound games such as chess). Many researchers have commented on Caillois' work [Frasca 1999; Bateman 2006a], and on the whole the basic form is accepted as applicable to computer games. Due to our focus (in later sections of this article) on the cognition of gamers, we must note that these types are meant to reflect the attitude or mind state of those playing, rather than objective attributes of the games themselves. On the basis of these typologies, we can posit some connections between game and player types, reflecting how such typologies are based on the motivations and attitudes of players:

(1) The conqueror type of player prefers games of agôn, as they provide the opportunity to measure one's capability against that of an equal opponent - that is, to prove oneself. This suggests a modern FPS game like Half-Life: CounterStrike [Valve 2001].

(2) The manager type would not enjoy alea, or any random elements in game- play, as this would detract from the sense of control - mastery requires agency; nor would he or she prefer ilinx, since it precludes complex control or rule systems. Games that combine agôn and mimicry are preferred, such as the empire building game, Homeworld (Relic 1999).

(3) The wanderer type could find enjoyment in most game types, but dislike of being constrained and challenged overmuch would tend to push such a player toward more paidic play. Certain racing games such as SSX 3 (EA Sports 2003), which contains very low-challenge touring elements, in addition to racing, would appeal to the wanderer type. 
(4) The participant types gives the least clear picture in the DGD study, but it seems that the hardcore participant prefers games with a strong story like ICO (Sony 2001); while the casual participant prefers social games such as Singstar (SCEE 2004). We can abstract the differences between these games to find the common thread - immersion in an activity or dynamic mental world, which is bounded and apart from "ordinary life," or simply participation in another world. Inasmuch as ilinx can be said to describe "ecstatic immersion" [Caillois 1962] that is not necessarily based on physical vertigo, this will be the participant's preference.

This illustrates how we can obtain a guideline for analysing a player by type within an information systems framework. The player typology suggests the motivation for play, which indicates the type of experience most likely to produce flow.

\subsection{Playing the Game - The Experience Segment}

The experience segment of the USE model shows the inter-relationship among several experience description constructs, which taken together can cover the range of feelings one might have in playing a game. Participation is an obvious and necessary starting point. Depending on the level of novelty and engagement, one can then either: disengage, experience telepresence, or begin to engage with and learn the game, possibly leading to an optimal experience. Telepresence describes the "experience of presence in an environment by means of a communication" [Steuer 1995], and is defined by the vividness of the experience: its breadth (number of senses involved), depth (degree of involvement), and the responsiveness of the system.

One complication is that common negative gaming experiences (such as frustration [Lazzaro 2004]) are interdependent with positive experiences (such as fiero [Lazzaro 2004] for some players (conqueror types; see Section 2.2). Fortunately this is accounted for by the construct we have used to study game-based optimal experience.

Flow is the experience description construct used in most computer mediated experience (CME) research. This term was coined by a leading researcher in optimal experience psychology, Mihalyi Csikszentmihalyi, who began his career studying the motivations of (board) game players, rock climbers, and painters [Csikszentmihalyi 1975a]. Interviewing people who were the acknowledged masters of a skill, such as surgery for instance, led him to conclude that such people often practiced their skill "not so much [for] the ability to cure the patient, or the money, or the prestige, but rather [for] the exhilaration of the difficult task that they are called to perform" [Csikszentmihalyi and Csikszentmihalyi 1990]. In the case of skilled and demanding leisure activities such as mountain climbing, this aspect is even plainer - one does not climb to reach the peak, one attempts the peak in order to climb - the activity is autotelic (auto $=$ self, telos $=$ goal), meaning that it is undertaken for its own sake. These "masters" used the term flow to describe the heightened and improved state of mind experienced while they were most engaged in a task and performing at their best. Csikszentmihalyi expanded his work to study people during their ordinary lives, using the experience sampling method research tool [Csikszentmihalyi and Csikszentmihalyi 1990]. On the basis of these empirical studies, Csikszentmihalyi specified eight major elements of the flow experience (Table I) common to the majority of people during optimal experiences.

He also formed the hypothesis that flow occurs as the balance between perceived skills and challenges [Csikszentmihalyi 1975a], thus what he calls the "flow channel" is a linear function on a plane with skills and challenges as axes (Figure 6). An increase in 
Table I. Elements of Flow

\section{Flow Elements}

A challenging but tractable task to be completed

One is fully immersed in the task, no other concerns intrude

One feels fully in control

One has complete freedom to concentrate on the task

The task has clear unambiguous goals

One receives immediate feedback on actions

One becomes less conscious of the passage of time

Sense of identity lessens, but is afterward reinforced

skills is due to learning, and an increase in the challenges of performing a task is due to novelty - keeping the two in balance is key to the Flow experience. However, Csikszentmihalyi's hypothesis was only partially confirmed by test data. Subjects experienced Flow when they first encountered a task with a high balance between skills and challenges. But when challenges and skills were initially low or when a task had to be repeated too often, apathy rather than engagement was reported, contradicting the Flow channel model. The disparity between test data and the original flow model was resolved when another researcher on optimal experience proposed the experience fluctuation model (EFM, Figure 7 [Massimini and Carli 1990]).

This model segmented the plane into eight parts, and test data from a study of Italian school-goers confirmed its accuracy [Carli 1986]. The factorization of flow into properties and the relative precision of the EFM is what made flow such a widespread and useful tool for studying computer mediated experiences.

Other researchers (a significant number are collated in Csikszentmihalyi and Csikszentmihalyi [1990]) independently expanded the study of flow to include other social groups around the world, and eventually a model of the psychology of optimal experience was formed. It is simply unfortunate that (to our knowledge) no comprehensive study ever included a group of computer game players. Without empirical studies, how can we say that computer games can produce flow? Our intuitive answer is that as gamers we have experienced what we call Flow while playing games. Yet is this experience what is really described by Flow? In the activities studied in the original work

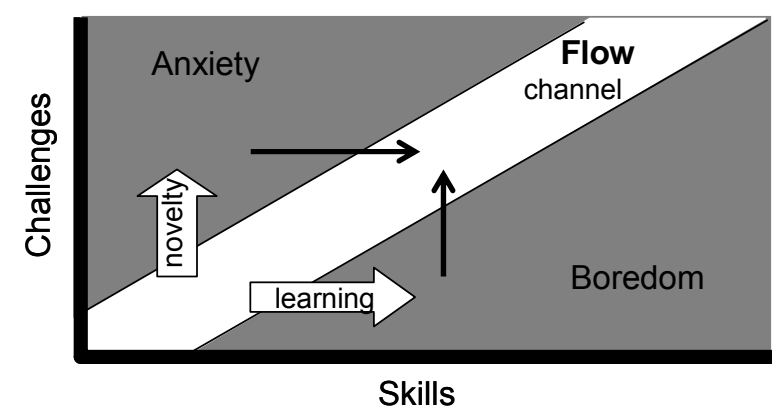

Fig. 6. Three dimensions of experience (anxiety, flow, boredom): flow channel diagram. 


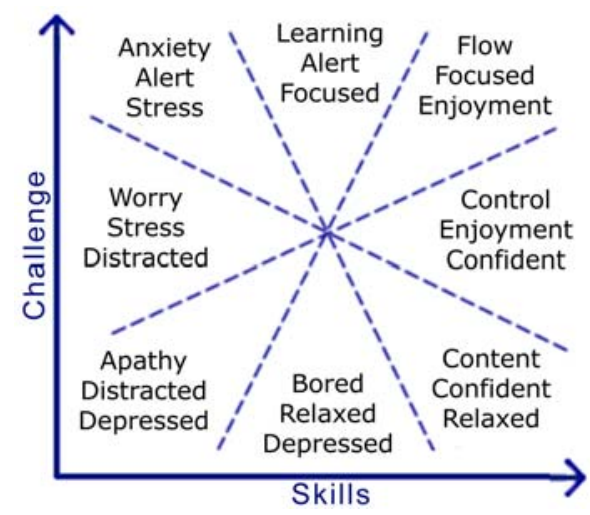

Fig. 7. Eight dimensions of experience: the experience fluctuation model diagram. Midpoint on the graph are a person's average skills and challenges for an activity.

by Csikszentmihalyi, Flow only came after a level of expertise was reached, following rigorous training 'off-the-job', which sets them apart from more accessible activities such as game-playing where training is part of the activity, and the full breadth (if not depth) of the experience can be obtained almost from the beginning of play. Does this imply that flow is only experienced while pursuing certain types of high-skill activity? Or that the individual concerned must have invested significant effort in training for the activity?

Csikszentmihalyi's theory states that it should be possible for any person to experience Flow in any activity, but that the participant and the activity must meet certain prerequisites before Flow can occur. Of these, perhaps the most important are that the person should have an autotelic personality (the ability to recognize and seize upon opportunities for flow) and that his or her skills match the activity's challenges in precisely the right ratio. Csikszentmihalyi's formula for meeting these prerequisites is rigorous self-improvement, which, while laudable, begins to imply that only considerable investment of time and effort can bring about flow.

But flow is isomorphic across all types of people studied - it is a universally uniform state of being, and all people recognize it when it is explained to them [Csikszentmihalyi and Csikszentmihalyi 1990]. Thus it stands to reason that universal cognitive states are inherent in the flow experience, and if this is so then there must be certain types of universally accessible activity that pre-empt and enable these cognitive states. We hypothesize that some activities will facilitate flow far more easily than others- for anybody, regardless of their skill in that activity - and that games are one of these activities. We believe this is so because the cognitive state necessary for the activity closely matches that achieved when in flow. An individual's propensity for happiness, brain chemistry, and capacity to concentrate will still impact their ability to experience flow, but the point is that the individual will start off that much closer to the cognitive state achieved in flow, by simply pursuing activities of this class.

In order to argue the validity of our hypothesis, that is, that games can offer a particularly flow-inducing activity with a low-investment threshold, we will look at games and player interactions as information systems and then examine how flow works in terms of information systems. Why formulate the structure and operation of gameplaying in terms of information systems? Consider the USE model (Figure 2). It relates games and players through the common thread of their interactions. But in order to 
describe how that interaction works, we need to be able to relate the operation of each entity during interaction. In other words, player modeling is implemented to improve player experience, but this can only be achieved by manipulating game dynamics, and this interdependency means we need a framing scheme that allows some kind of translation between games, player interaction, and the flow construct. For such a framework we have chosen to use the information systems paradigm described in Section 4. To situate the discussion, we first look, in Section 3, at similar work in the literature.

\section{THE RELATIONSHIP BETWEEN GAMES AND FLOW}

When we notice similarities between two different systems...the comparison often begins in a literary manner. There is the simile, the more direct metaphor, conceptual models...The process continues, and begins to have the marks of a scientific method, when we try to develop rigorous formulations of the two conceptual models. [Esperjo and Harnden 1989]

In comparing these two distinct theoretical models of activity and experience, we began with the original literature. Flow was conceived during studies into motivational psychology via game-playing [Csikszentmihalyi 1975b], and references to games in the flow literature, as below, point to similarities in their objectively verifiable operation.

Flow is a sense that humans have developed in order to recognize patterns of action that are worth preserving and transmitting over time. This was Huizinga's great insight: that the "serious" institutions that constitute society - science, the law, the arts, religion, and even the armed forces - all started out as games, as context in which people could play and experience the enjoyment of goal-directed action. [Csikszentmihalyi and Csikszentmihalyi 1990].

We must note Huizinga's importance as a foundational thinker in the study of gameplay because comparing his definition of play to the primary definition of Flow illustrates a striking similarity between them.

Play is a voluntary activity or occupation, executed within certain fixed limits of time and place, according to rules freely accepted but absolutely binding, having its aim in itself and accompanied by a feeling of tension, joy, and the consciousness that it is "different" from “ordinary life”. [Huizinga 1949]

When goals are clear, when above-average challenges are matched to skills, and when accurate feedback is forthcoming, a person becomes...so involved in an activity that nothing else seems to matter; the experience itself is so enjoyable that people will do it even at great cost, for the sheer sake of doing it. [Csikszentmihalyi and Csikszentmihalyi 1990]

In this comparison we see that similarities sometimes agree in nature but not in scope, implying that flow and play intersect rather than equate (computer games can but do not necessarily give flow). Any parallels to be drawn here are between definitions made in unrelated bodies of research, many years apart, and it is this rather than the rigor of the equalities that lends them credence. However, there is little enough of substance to be gained, and this comparison merely helps to set us on the right track and set the scene. It is in the factorial nature of the flow construct that we can look for an operative analysis.

Researchers other than Csikszentmihalyi have also seen a natural link between flow and games, including Mitchell [1990], Massimini et al. [1990], Sato [1990], and Rathunde [1990]. Nakatsu [2005] published a review of work on the cognitive operation of the antecedents to flow, which gives (in information system terms) an insight into the 
reasons that flow might occur in a CME. The Novak et al. [2000] in their study of CMEs indicate that flow is directly affected by skill/control, challenge/arousal, and telepresence/time distortion. The first two pairs are affected in turn by interaction speed and importance, while the last is affected by focused attention. In researching enjoyment in interactive hypertext, Douglas and Hargadon [2000] used schema theory to define the terms engagement and immersion.

The pleasures of engagement tend to come from our ability to recognize a work's overturning or conjoining conflicting schemas from a perspective outside the text, our perspective removed from any single schema. Our enjoyment in engagement lies in our ability to call upon a range of schemas... The pleasures of immersion stem from our being completely absorbed within the ebb and flow of a familiar narrative schema. [Douglas and Hargadon 2000]

They argue that immersion relates to recognition/comprehension, and engagement to problem-solving. They go on to formulate a definition for flow in these terms, saying that one experiences flow by engaging with a complex domain until it is fully known, at which point immersion lasts until the domain becomes more complex. Only if complexity increases can the ratio of challenges to skills in the activity revert (toward initial levels),

Table II. Eight Elements of Flow and Corresponding Game-Play Attributes; from Jones [1998]

\begin{tabular}{|l|l|}
\hline \multicolumn{1}{|c|}{ Element of Flow } & \multicolumn{1}{c|}{ Manifestation in a game } \\
\hline $\begin{array}{l}\text { 1. Task that we can } \\
\text { complete }\end{array}$ & $\begin{array}{l}\text { The use of levels in games provides small sections } \\
\text { that lead to the completion of the entire task. }\end{array}$ \\
\hline $\begin{array}{l}\text { 2. Ability to concentrate on } \\
\text { task }\end{array}$ & $\begin{array}{l}\text { Creation of convincing worlds that draw users in. } \\
\text { The dungeons and labyrinths in Doom II help } \\
\text { suspend your belief systems for a time. }\end{array}$ \\
\hline $\begin{array}{l}\text { 3. Task has clear goals } \\
\text { 4. Task provides } \\
\text { immediate feedback }\end{array}$ & $\begin{array}{l}\text { Shoot people and they die. Find a clue, and you } \\
\text { can put it in your bag. }\end{array}$ \\
\hline $\begin{array}{l}\text { 5. Deep but effortless } \\
\text { involvement (losing } \\
\text { awareness of worry and } \\
\text { frustration of everyday) }\end{array}$ & $\begin{array}{l}\text { The creation of environments far removed from } \\
\text { what we know to be real helps suspend belief } \\
\text { systems and takes us away from the ordinary. }\end{array}$ \\
\hline $\begin{array}{l}\text { 6. Exercising a sense of } \\
\text { control over their } \\
\text { actions }\end{array}$ & $\begin{array}{l}\text { Mastering controls of the game, such as a mouse } \\
\text { movement or keyboard combinations. }\end{array}$ \\
\hline $\begin{array}{l}\text { 7. Concern for self } \\
\text { disappears during flow, } \\
\text { but sense of self is } \\
\text { stronger after flow } \\
\text { activity }\end{array}$ & $\begin{array}{l}\text { Many games provide for an environment that is a } \\
\text { simulation of life and death. One can cheat death } \\
\text { and not really die People stay up all night to play } \\
\text { these games. It is the creation of an integration of } \\
\text { representation, problem, and control over systems } \\
\text { that promotes this. }\end{array}$ \\
\hline $\begin{array}{l}\text { 8. Sense of duration of } \\
\text { time is altered. }\end{array}$ & $\begin{array}{l}\text { Years can be played out in hours; battles can be } \\
\text { conducted in minutes. The key point is that people } \\
\text { stay up all night playing these games. }\end{array}$ \\
\hline
\end{tabular}


and flow be maintained. This shows that the activity context must be dynamic or flow will be short-lived. In the original flow case studies the need for novelty was the reason why subjects like rock climbers or chess players were forever in search of new settings and challenges such as a new rock face or a better chess opponent. It also explains the addictiveness of games, which are based on novel settings for challenging activities in a manner deliberately structured to produce an optimal experience.

\subsection{Dimensional Comparisons of Games and Flow}

Other researchers in game studies have mapped the basic, universal "building blocks" of games into dimensions similar to the eight-fold factorization of flow as well. This mapping has been used to show how games can be explicitly formulated as flowproducing activities by Jones [1998] (Table II) and Sweetser and Wyeth [2005, pp.4-5]. The former was motivated by trying to build more engaging computer-based learning environments (CBLEs). The logic is that since games seem to be highly engaging to large portions of the population, taxonomizing them in relation to flow theory would highlight elements that could be exported to CBLEs. The motivation was to build a model to aid analysis of what causes games to be enjoyable - a motive closer to that of the authors of this article.

On first sight, the mapping in Jones [1998] appears quite comprehensive. However, we can see repetitions from the $2^{\text {nd }}$ to the $5^{\text {th }}$ rows, and the $7^{\text {th }}$ to the $8^{\text {th }}$ rows (Table II), which shows a lack of insight. Also, we consider that there are some key misapprehensions for which we offer the following caveats:

(1) The "task that we can complete" is primarily delimited by the player's desire to play, not by a level structure. The "goal" in flow's "goal-directed action" doesn't have to be explicitly provided by the action, like goals in football. It is provided by the desire to expend effort in taking part: the autotelos of participation.

(2) It is important that the "immediate feedback" in games is suitably patterned (with respect to attentional finitude and flow) so that the participant can absorb the information optimally. Contingencies are patterns of distribution of reinforcers in behavioral psychology [Hopson 2001], and variable ratio and variable interval contingencies are suggested for improved game-play. Most games that get this right do so by play-testing and balancing an expert's design; it is very much case-by-case, and there is as yet no "magic formula" to get it right the first time.

(3) In order to "exercise a sense of control," a player must often be familiar with the genre and its conventions, since modern games can be a self-referential media.

As the mapping by Sweetser and Wyeth [2005] is too large to include here, we can only address it in summary. Their table corresponds several requirements to each flow element, thus defining what elements a game should have in order to provide flow. This works when scoring existing games for their flow-providing capacity.

However, we feel the mapping does miss some important points at the elementary level. Most importantly, we consider the task attribute from the flow model to equate to the game session that the player "sits down to," whether it be a solitary or a social activity - thus there is no need for an extra game dimension representing social interaction. This should be clear from Csikszentmihalyi's [1975] use of chess players (the game of chess 
did not exist in computer form at the time!) to study flow. Looking at the expanded table, the idea that concentration relates to quantity of stimuli contravenes the Yerkes-Dodson law [Yerkes and Dodson 1908]. We also question whether social interaction is a necessary or even desirable part of every game - if one equates immersion with recognition of existing schemas as in Douglas and Hargadon [2000], social interaction precludes schemata involving solitude, like the sensation of driving a vehicle. Yet this is clearly belied by such long-running, popular vehicle-control games as Microsoft Flight Simulator X (Microsoft 2006). Finally, the requirements are mostly subjective - what is appropriate for one player may be totally inappropriate for another. In Table III we give a mapping in line with Table II, that is more congruent with our hypothesis on games and Flow.

Unfortunately, there are problems with the entire idea of model mapping as presented, our own mapping included. The main problem is that an over-literal approach to comparing elements from games with the eight dimensions of flow does not provide the desired rigor. The descriptions of Flow in (Figure 6 and Table I) are just models, useful in understanding a system [Esperjo and Harnden 1989], but any model is just a representation of the particular set of invariances we are interested in. Thus in mapping between two systems, there are two sets of invariances that are of interest and must be transformed, not two models. Since models are by their nature inexact representations, transforming one directly risks that the result, undetected during mapping, will show properties not found in the process it imitates or not possess properties possessed by the process it imitates.

Mapping between one system and another should be done at the level of systems, not by models describing the systems, since in effect models are only mappings from the

Table III. Eight Elements of Flow and Corresponding Game-play Elements

\begin{tabular}{|c|c|}
\hline Flow Elements & Game-play Elements \\
\hline $\begin{array}{l}\text { A challenging but tractable task to } \\
\text { complete }\end{array}$ & $\begin{array}{l}\text { The complete gaming experience } \\
\text { (including social interaction during game- } \\
\text { play). }\end{array}$ \\
\hline $\begin{array}{l}\text { Full immersion in the task, no } \\
\text { other concerns intrude }\end{array}$ & $\begin{array}{l}\text { High motivation to play, no imperative to } \\
\text { do otherwise; empathetic to content. }\end{array}$ \\
\hline Feeling of full control & $\begin{array}{l}\text { Familiarity/skill with controller, genre } \\
\text { conventions, game-play mechanics. }\end{array}$ \\
\hline $\begin{array}{l}\text { Complete freedom to concentrate } \\
\text { on the task }\end{array}$ & $\begin{array}{l}\text { Telepresence [Steuer 1995] and an } \\
\text { environment dedicated to gaming. }\end{array}$ \\
\hline $\begin{array}{l}\text { The task has clear unambiguous } \\
\text { goals }\end{array}$ & $\begin{array}{l}\text { Missions, plot lines, levels; any explicit } \\
\text { outcome of a successful play session. }\end{array}$ \\
\hline Immediate feedback on actions & $\begin{array}{l}\text { Well-timed, suitable rewards and penalties: } \\
\text { contingencies [Hopson 2001]. }\end{array}$ \\
\hline $\begin{array}{l}\text { Being less conscious of the } \\
\text { passage of time }\end{array}$ & $\begin{array}{l}\text { Focusing on another, temporally- } \\
\text { independent environment. }\end{array}$ \\
\hline $\begin{array}{l}\text { Sense of identity lessens, but is } \\
\text { reinforced afterward }\end{array}$ & $\begin{array}{l}\text { Embodiment in game avatar; sense of } \\
\text { achievement after play - e.g.,"Hi-Score" }\end{array}$ \\
\hline
\end{tabular}


systems to a set of definitions understandable to humans. In this light, the next section might be thought of as a description of flow and games at the level of their lowest common denominator of operation - the processing of information.

\section{GAMES AND PLAYER INTERACTION AS INFORMATION SYSTEMS}

Games generate complex emergent behavior, as the formal structures of rules facilitate the unpredictable experience of play. [Salen and Zimmerman 2003]

By information system, we mean any complex system that takes input, processes it and/or outputs it. An information system that learns is a complex adaptive system. If we incorporate learning to an information processing system, we must deal with novelty and the difference in information before and after transmission (information is contextdependent - it cannot be the same before and after reception). Information theory systems are a subset of information systems that are mathematically defined and apply to communication channels [Shannon and Weaver 1963]. Shannon's communication theory is useful in representing isolated interactions, but assumes ergodicity, which means it cannot be used to represent a learning system over time. The principle of observer independence also limits this and other solutions [Crutchfield and Young 1991]; if we accept that this principle is not tenable in a description of interactive computing [Lieberman and Selker 2000] (or as some would contend, even in physical reality [Smolin 2003]), we must move to an observer-dependent, interactive view of information systems (all references to such use lowercase). Only in static, non-learning cases do we refer to Shannon's construct using the capitalized word Information (the technical term Uncertainty is also referred to in this manner).

\subsection{Games as Information Systems}

At heart, games are computer programs and thus, when discussing games as information systems, there is an issue of clarity since any computer program can be described using the mathematical formalisms of information theory [Holland 2000]. This formal description of information transmission in game code is not our current focus - we are looking at how information travels from game to player, and back. We do have some use for information theory, however, so in order to disambiguate we first look at Shannon's Information, before moving on to the less formal sense of games as information processing systems, which will help us relate them to players and the flow experience. Sid Meier said that games are "a series of meaningful choices" [Salen and Zimmerman 2003]. Information as defined in information theory does not deal with subjective meanings, but it can relate to transmissions in the interaction that occur during gameplay.

In a sense, the information in a communication system is analogous to the space of possibility in a game. The sender of an information-rich message is choosing from many potentially meaningful possibilities. The player in a game with a large space of possibilities is selecting an action from among many possible meaningful options as well. [Salen and Zimmerman 2003]

We can say that symbols, visual cues and entities, controller feedback, and so on carry "bits" of information, and their total gives the player's potential Uncertainty about the current game state. We say potential because we cannot know whether the player is actually more Uncertain than we predicted because he/she is not paying attention to all the "bits" of Information; or is less Uncertain because he/she has a priori knowledge (for 
instance, due to having played the game before). This is the first large issue with the games as Information Theory systems approach, and would only be tractable at great cost [Isokoski and Martin 2006; Jonsson 2005]. The second issue is trying to classify the "bits" of Information. This is more tractable because, as we have shown (Section 2.1), games have a formal structure and so the task is to identify atomic entities (at the level of Operative rules) that represent formal elements at the level of Constituative rules. Of course, signal transmission is subject to noise, and for a game, this is anything that obscures the player's reception of the game's meaningful content. Salen and Zimmerman [2003] point out that noise is not necessarily a bad thing: as it increases Uncertainty, it can deepen the complexity of the "puzzle" presented to the player, and thus increase the lifespan of the game. For example, as game physics has advanced, driving games (Colin McRae DiRT, 2007, Codemasters) now include real environmental and weather effects, requiring the player to make a more thorough analysis of information to gauge likely car behaviour, and so force more involved game-play. On the other hand, games also make significant use of redundancy. Meaningful content in the game world is restricted more by convention than by necessity (e.g., an FPS might use robots or aliens as opponents, but is unlikely to use anthropomorphic fruit). To reduce unnecessary Uncertainty, every action-capable entity other than the player in predator/prey and older action games will often be an enemy. Hence the information the player receives about the appearance of a given enemy NPC (i.e., the 3D model rendered onscreen) is highly redundant, as the player only needs to see movement to recognize an enemy.

Shannon and Weaver [1963] expressed their Information concept as freedom of choice in selecting a message. This idea is important to us, because for a human the act of selection is a matter of cognitive processing, and so constraints on human cognition come into play. There is too much freedom, too much Information, precisely at the point when they exceed an individual's attention span. If an individual can't pay attention to everything required to make a choice, he or she will feel overwhelmed. We might say that the challenge of choosing is greater than the skill they can bring to bear. Similarly, if there is little Information, there is little freedom to choose. The result of the choice is quite certain and the individual will be intrinsically motivated to regard the choice as already made. They will instead look ahead to the next state of the system and the current choice will be boring to him or her.

In the same sense that games can be regarded as Information Theory systems on the Constituative level, they are systems of information (meaningful content) on the Operative level; that is, players see and interact with meaningful content. This information is structured in the game and brokered to the player in a multitude of ways across a variety of games - for modern games especially. According to Pearce [1997], information in physical, non-digital games is structured in four ways. For digital games, the intricacy of what a computer knows (about the game it runs) makes the concept of 'player' a little harder to define than usual. For modern games the opponent A.I. is usually agent-based, so NPC knowledge is limited in the same way as the player's.

(1) Information known to all players: A simple rule of thumb is that information that is available equally to the human player and all their nominal opponent(s).

(2) Information known only to one player: In an RTS, the fog of war feature means a player usually starts with his troop types and disposition hidden from the enemy.

(3) Information known to the game only: No players have this information, but the computer does. (e.g., areas of an RTS map covered by fog of war for all players). 
(4) Randomly generated information: Information that can't be known before it is generated. Even in a deterministic pseudo-random number generator algorithm, if the seed is arbitrary then predicting the number is the same as generating it.

If the game contains information of the first two types only, it corresponds quite closely to the idea of perfect information. How information in the game moves from one type to another is at the core of how the game provides meaningful play, because this happens due to some agency. The key is whether the agency is given to the player or to some predefined dramatic narrative, or left to chance. Consider the fog of war in RTS games. If the fog of war is taken away, the game removes the need for the player to explore, and thus to decide where to explore, and thus reduces their agency. It also reduces uncertainty and the freedom to choose - if you know where your enemy is, you're not going to march in the opposite direction. Limiting agency and uncertainty ultimately reduces the challenge, and thus the potential for a sustained optimal experience.

\subsection{Player Interaction as an Information System}

In terms of cognition, complexity relates to how we differentiate and integrate perceptual input to enable us to build analogies so that we can deal with a persistently changing world [Rauterberg 1996]. The more complex our comprehension of the context, the more data we can parse at a time; this is also defined as chunking [Miller 1956]. An expert in a topic will have a richer comprehension of that topic, and thus a more complex internal model of the topic context. Rauterberg [1995] proposed measuring the complexity in a learning system (here, the player) and its context, and developed the model shown in Figure 8 to describe the relationships involved. Context is a difficult concept to pin down, Lieberman and Selker [2000] define it as everything except input and output; but in Rauterberg [1995] it is defined as all input, output, and externally generated, perceivable information. Thus total complexity includes both the environment and the system's interaction with it - everything but internal processing.

The complexity of the context (CC) equates to the environmental complexity (EC) summed with the bodily complexity (BC; e.g., measured by level of arousal). The complexity of the system equates to the internal complexity of the memory (MC), or task-related mental model. Task-related memory is similar to an individual's problemsolving schema [D'Andrade 2005].

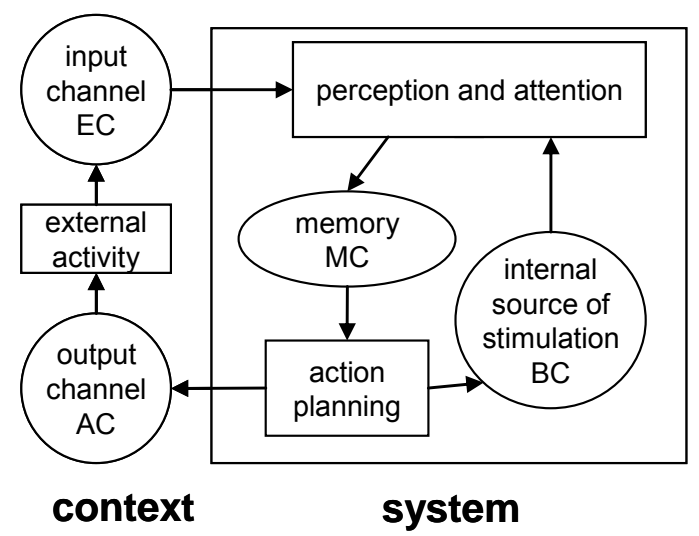

Fig. 8. Adapted from the Rauterberg [1995] model of a learning system. 


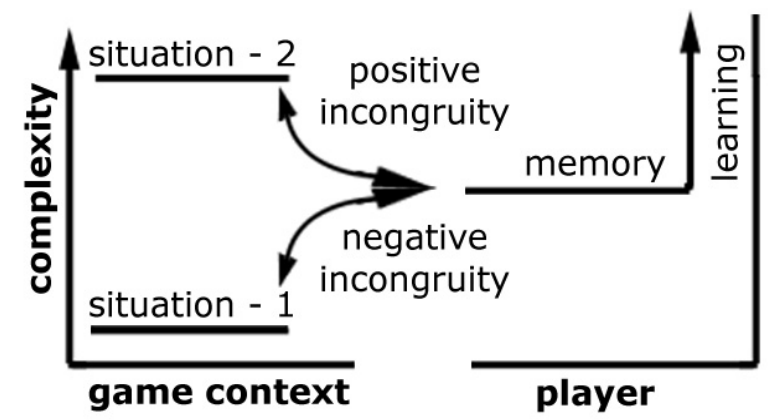

Fig. 9. Adapted from Rauterberg [1995]: "the difference between the complexity of the mental model and the complexity of the context is called incongruity".

The term incongruity (from Hunt [1963]), describes the relative disparity between the complexity of an internal model and external context (Figure 9), and thus correlates to the player's comprehension of the game context. Information processing is an interactive concept and is observer-dependent; it is also an optimization process, as learning involves collating processed information. The exact nature of this is described in different ways as chunking [Miller 1956]; as schema-building in schema theory and so on [D'Andrade 2005].

The attractors for this information optimization (Figure 10, at the intersection of the two tendency curves) are constrained by the individual's mental model, including the current- and memory-context. Assuming that their optima also agree with the teleonomic goals of the individual (i.e., collating information is done to aid self-optimization); the tendency is to structure knowledge of the context into schemata that support pursuit of self-reinforcing goal states. Thus activities that provide familiarity and novelty at the same time will tend to engender more intrinsic psychological reinforcers. It may be helpful to look briefly at how our brains treat information from a neuro-physiological viewpoint, as recent research supports both the information processing formulation above and our hypothesis on flow in games.

Csikszentmihalyi and Csikszentmihalyi [1990] and Koster [2005] claim that after satisfying the basic needs of survival and procreation, humans are driven to maximize the rate at which they acquire new but interpretable information. The term Infovores was

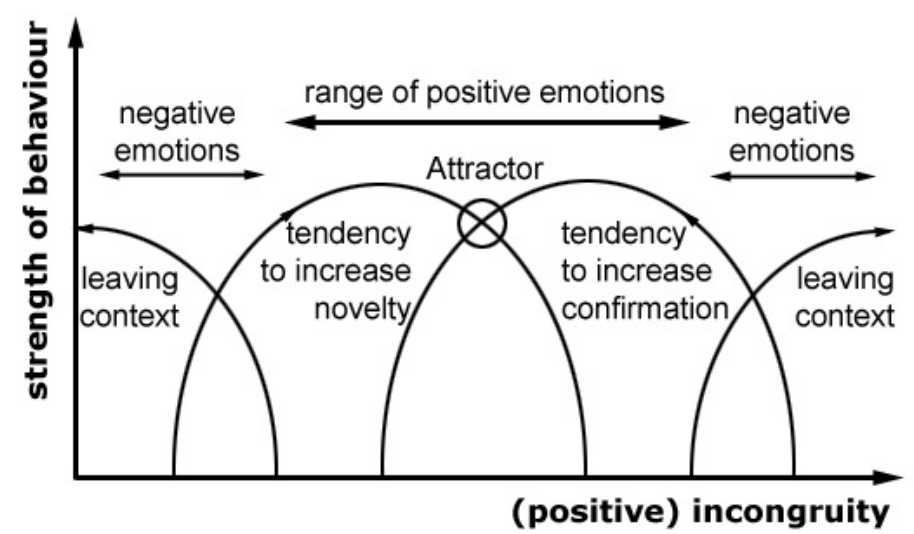

Fig.10. Adapted from Rauterberg [1995]: "the coherence between positive incongruity, emotions and observable behavior".

ACM Computers in Entertainment, Vol. 6, No. 2, Article 20, Publication Date: July 2008. 
coined by Biederman and Vessel [2006] to describe this behaviour. Their neurophysiological studies revolve around building a motivational explanation for the human perceptual cognitive system and relates directly to both Flow (motivation) and games (perceptual cognition). It has been established (from 1968 on) in studies on visual attention [Kahneman 1973; Brown and Gregory 1968] that spontaneous looking is largely governed by a scene's novelty and complexity; that is, we focus mainly on regions where something novel is happening and where we can interpret what we perceive. In their investigation of why this is so, Biederman and Vessel [2006] found that experiencing novelty can actually cause neuro-physiological pleasure in the same way as drug use. In simple terms, the mu-opioid chemical receptor which is found on the surface of some brain cells is activated by endorphins (and heroin or morphine), and is found in areas of the brain that mediate pain and pleasure but also in areas that process sensory information and memories. Mu-opioids occur in increasing numbers along neural pathways such as the ventral cortical visual pathway [Lewis et al.1981; Wise 1982], from the early stages in which processing basic things like colour takes place (visual cortex) to the later stages of conscious recognition (periamygdalar cortex).

These areas become active when the brain is trying to interpret sensory information, whether that is graphical, textural or textual (this event may be similar to the auditory processing pathways; although we are not aware of similar research on audio processing). Biederman and Vessel [2006] suggest that when this happens, the endorphins that stimulate mu-opioid receptors are released, and the individual experiences a feeling of pleasure. Novel input will be either incomprehensible (perhaps because it is too entropic), or relate to some greater or lesser degree to an individual's memories. Thus input will require more or less processing as it is interpreted and associated. Due to the constant increase in the number of mu-opioid receptors along the neural processing pathway, the more processing that is done, the more pleasure will be experienced. Hence information that triggers the most memories and conveys the most meaning to a person causes the greatest pleasure response.

Repetition decreases the effect when comprehension keeps up with "consumption” (as the information is no longer novel). Repetition is acceptable as long as comprehension lags. Biederman and Vessel [2006] say that endorphins are released at the moment (or "click") of comprehension. Children take longer to "click" than adults, which explains their enthusiasm for repeatedly watching the same film.

The instant that the correct answer rings out - the signal coming full circuit, the noise and uncertainty finally overcome - is a deeply satisfying moment of play. [Salen and Zimmerman 2003]

We suggest that a learning system that collates new information and finds high utility in novel information that is related to what has been collated will develop a teleonomic principle that requires it to seek out new information that is interpretable because it is relatable - not just simple. We call this the teleonomic principle of novel but relatable information gain, which is the pattern of information processing that players experience in the mechanics of almost all game-play. When the learning system is a person, the utility could simply be physical pleasure, as suggested by Biederman and Vessel [2006]. But physical pleasure is generally associated with genetic teleonomy [Csikszentmihalyi and Csikszentmihalyi 1990], whereas the gaming experience seems to serve only the consciousness, and thus the teleonomy of the self. So a more subtle utility for the player is needed, which is where flow comes in. 
4.3 'Flow' In Information Systems

The method shown in Section 3.2 (linking antecedents of flow to attributes of game-play) is one plausible way to demonstrate the relationship, but we prefer to examine the operational structure of each experience separately using a single framework, thereby exposing any hint of their relational operation. We can consider flow as the state of optimal operation of an information system, which is defined here as a person pursuing a bounded activity such as game-play. We can then begin to formulate the operation of flow within the framework used above to describe other systems (games and brains).

In Section 4.2 we described how an individual could process information by (unconsciously) optimizing it according to personal goals. If we say that flow is such a goal state, we can posit that an individual's information processing (or learning) will be structured so that continuation of the flow activity is prioritized. This could be related to producing such side effects of Flow as mentioned above (rows 2, 7, and 8 in Table I); it follows that "sense of control" and "freedom to concentrate" will be present if all optimization of learned information supports Flow-producing activity.

It should be noted that in order to describe flow as occurring within an information system, we must assume (rather than define or observe) some elements of the full description of an individual experiencing it - namely, we cannot satisfactorily consider the person's affect (without specialist hardware) or their autotelic personality [Csikszentmihalyi and Csikszentmihalyi 1990] in the framework of an information system. However, it can be argued (based on the flow antecedents in Table I) that in order for a person to experience flow in the first place, they will already (to some degree) be in a emotional state conducive to such an experience and have an autotelic personality. So we can safely abstract these elements without compromising the validity of the description.

The self represents its own interests as goals. Each self develops its own hierarchy of goals, which become, in effect, the structure of that self. Whenever a new experience enters consciousness it is evaluated in terms of the goals that reflect the self, and it is dealt with accordingly. A bit of information that fits these goals strengthens the structure of the self, whereas one that conflicts with them creates disorder in consciousness and threatens the integrity of the self...We use the term psychic entropy to refer to those states that produce disorder by conflicting with individual goals. Psychic entropy is a condition in which there is noise in the information-processing system.... at the opposite end of the pole...is the condition we have called psychic negentropy, optimal experience, or flow. [Csikszentmihalyi and Csikszentmihalyi 1990]

Thus psychic entropy is a disorder in the subjective state of the individual (noise in the information processing system), and individuals naturally seek out negentropic states by attempting to lower this noise. In defining the relation between flow and information, based on the above, we might say that flow is low noise in the context that we experience when performing a given task. Flow is a subjective measure, so the context includes both internal and external complexity, which means that "noise" must be low in both the input from external complexity (stimuli) and internal complexity (cognition). If we frame the operative cognition in flow theory in terms of schema theory, saying that comprehension is a product of schema-building and that problem-solving is a mental model that maps between current schemas (which may adapt dynamically) and current stimuli, then we can view the skills axis of the flow channel as the individual's internal complexity and the challenges as external complexity. 
Meeting the challenges with appropriate skills (the core antecedent of flow) will then be a matter of balancing incongruity, as in Rauterberg [1995]. That is, challenge in gameplay is generally proportional to the rate of information gain. Skill is proportional to performance set against both challenge and optimal potential performance. Both metrics must be supported with profiling, since they require persistent data and some player background in order to accurately define flow. For instance, in game types that require some skill to control, only a portion of current challenges can be expressed as a function of current information gain, since there are antecedents to play that correlate to training. Thus the challenge of the player's training must be calculated and saved from the beginning of play. Skill is also tied to this training data, and both are affected by data such as the "number of replays" and "other games played."

\subsection{Relating Systems}

Aside from its intrinsic motivation, our theoretical analysis has the future goal of informing practical methods to build adaptive games which can improve player experience. There are considerable issues involved in adaptive games, which we do not have the room to address here. But a key question is how what we have examined here can be used to address player experience in practice?

We have shown how games can be specified by formal descriptive languages, (e.g., as a collection of nouns and verbs). This is an intuitive description, as it comes close to what the player sees. Hence we can formulate an information system framework so that content-communicated information can be calculated in real-time. The Flow construct, as applied to game-play experience, can also be described using the information systems paradigm when the information processing in game-play permits appropriate metrics for measuring challenge and skill. Assuming it is possible to correlate, through experiment, player types with the values of the challenge/skill metrics, we posit that a system could be built to dynamically adjust information-carrying game entities to adapt the operational details of game-play such that the player's experience is smoothed more toward its optimal - their personal information processing attractor. Adjusting the entities measured is not done to put players in the flow, but to make games reactive to individuals through tangible aspects of their experience, for which affect is adjudged by heuristics derived from the flow construct.

Such an automated system, which can objectively (albeit approximately) evaluate cognitive and emotional states of gamers as they play, is a necessary lynch-pin of any adaptive features in a game engine, which in turn is needed to affect the player's experience in real-time. Advances in low-level methods for player-centered adaptivity have been modest but steady [Yannakakis et al. 2004; 2005; 2006; Spronck et al. 2005; 2006]; the major challenge is to develop them into more generic, universal solutions that can be integrated, as they address many facets of the same problem. To enable such integration, that is, to increase our theoretical understanding of gaming in operation, we hold it important to investigate the possibility of invariances across systems in real-time game-play.

\section{CONCLUSIONS}

For an individual to attain flow in an activity a balance must be achieved between the external complexity of the system and the internal model that a user develops of that system. A user attains a more accurate internal model of the system through learning and practice - through an ongoing cognitive processing of the external complexity of the system. The attainment of a strong correlation between internal and external complexity is dependant both on the capability and willingness of the user/learner to master the 
system and on the quality of system design to meet the requirements and capability of the user. Ideally, complexity in the system should be revealed as required by the user.

We hypothesized that games provide an activity that forces the player into a cognitive state which begins to approximate the flow state ${ }^{5}$. In support of this hypothesis we argue that, with the presentation of a rule-bounded optimization activity in an information-rich environment, what games are actually doing is creating psychic entropy and then providing the means to resolve this into a more negentropic state. Games have an ordered environment (noun sets), with opportunities for action in the form of controls (verb sets); and these are almost always simpler to start with, advancing in complexity as familiarity and thus mastery increase. For example, in a scrolling shooter game the pattern is that one faces and kills varieties of enemies that come in turn (generally with some overlap) until the end. New enemy types relate to previous types, and increase in power, which usually means the complexity of killing them increases. But the overall complexity of the task is ameliorated by the relation of new to old information, thereby (in a well-balanced game) producing that ongoing cyclic balance between (cognitive) challenge and skills so necessary for flow to occur.

Since the game is resolved through the player's own agency, he or she gets the sense of control and challenges met with appropriate skill that differentiate games from the psychic entropy inherent in a film, book, or other media. Because it is media and not reality, there is a low investment threshold - we do not need to buy a racing car, rock climbing equipment, or a big gun (BFG), and there are none of the associated risks - we do not need to race a car, climb a rock, or go hunting. Mastery of a structured challenge within a model world requires the dedication to learn and apply skills, but as it is a model world, the level of collateral investment is entirely discretionary to the world's designer in other words, training in games is almost always on-the-job. As a result, games give immediate access to their inherent potential for optimal experience, and that potential is facilitated by the structured nature of further game-play. Thus there is a common correlation between simply completing computer games and getting "in the flow". As [Koster 2005a] might say, this is 'grokking' the pattern of the game.

\section{AUTHOR STATEMENT}

The work presented draws together all of the author's research on methodological reasoning on player behavior in computer game-play. This work was initiated with the paper "User-System-Experience Model for User Centred Design in Computer Games," which outlined how a player might derive experience from a game and how that might be used to adapt game-play. A process for collecting data on the player in-game, so that the theoretical methods outlined above could be actualized, was proposed in the paper "Using Decision Theory for Player Analysis in Pacman". These disparate papers meet at the point where games are considered as information systems, which is the focus of this article.

\section{REFERENCES}

ABT, C.C. 1970. Serious Games. Viking Press, New York.

AVEDON, E.M. 1971. The Study of Games. Wiley, London.

BARTLE, R. 1996. Hearts, clubs, diamonds, spades: Players who suit MUDs. J. Virtual Environments 1, 1 (June).

Bateman, C. And Boon, R. 2005. 21st Century Game Design. Charles River Media, London.

BATEMAN, C. 2005. Riddles of difficulty.

http://onlyagame.typepad.com/only_a_game/2005/11/riddles_of_diff.html. Accessed May 2008.

\footnotetext{
${ }^{5}$ How far into a flow state the game can lead an individual may depend on how they relate to games as an activity, which will be mostly due to cultural influences.
} 
BATEMAN, C. 2006a. Roger Caillois' patterns of play. http://onlyagame.typepad.com/only_a_game/2006/05/roger_caillois_html. Accessed April 2008

BATEMAN, C. 2006b. Play specifications. http://onlyagame.typepad.com/only_a game/2006/04/play specificat.html. Accessed May 2008

BiedERMAN, I. AND VeSSEL, E.A. 2006. Perceptual pleasure and the brain. American Scientist 94, 249-255.

BROWN, L.T. AND GREGORY, L.P. 1968. Attentional response of humans and squirrel monkeys to visual patterns: Final studies and resume. Perceptual and Motor Skills 27, 3, 787-814.

CAILlOIS, R. 1962. Man, Play and Games. Thames \& Hudson, London. In English translation.

CARLI, M. 1986. Selezione psicologica e qualità dell esperienza [Psychological selection and quality of experience]. In L'esperienza Quotidiana: Teoria e metodo d'analisi [Daily experience: Theory and Methods of Analysis]. Franco Angeli, Milan.

Charles, D., McNeill, M., McAlister, M., Black, M., Moore, A., Stringer, K., Kerr, A., AND KuCKLICH, J. 2005. Player-centred game design: Player modelling and adaptive digital games. In Proceedings of DiGRA 2005 Conference: Changing Views - Worlds in Play (British Columbia, June 1620), 285-298.

CHOMsKy, N. 1956. Three models for the description of language, IRE Trans. on Information Theory 2, 2, 113-123.

CHuRCH, D. 1999. Formal abstract design tools. Game Developer Magazine (Aug.). http://www.gamasutra.com/features/19990716/design_tools_01.htm. Accessed May 2008.

CoOK, D. 2006. Creating a system of game play notation. http://lostgarden.com/2006_01_01_archive.html. Accessed May 2008.

CostiKYAN, G. 1994. I have no words and I must design. Interactive Fantasy J. 2.

Cousins, B. 2004. Elementary game design. Develop Magazine (Oct.). http://www.bencousins.com/. Accessed May 2008.

Cousins, B.. 2005. Low-level game design, atoms, measurement and hierarchies. Presentation at Game Developers Conference, Europe. http://www.bencousins.com/. Accessed May 2008.

COWley, B., Charles, D., Black, M., AND Hickey, R. 2006a. User-system-experience model for user centred design in computer games. In Proceedings of the 4th International Conference on Adaptive Hypermedia and Adaptive Web-Based Systems (Dublin, Ireland, June), V. Wade et al. eds., LNCS 4018, Springer, 419-424.

COWley, B., CHARles, D., Black, M., AND HiCKEY, R. 2006b.Using decision theory for player analysis in Pacman. In Proceedings of the SAB'06 Workshop on Adaptive Approaches for Optimizing Player Satisfaction in Computer and Physical Games (Rome, Oct.), G. N.Yannakakis and J. Hallam eds. Tech. Rep.TR-2006-2, Maersk Institute for Production Technology, University of Southern Denmark, Odense.

Crawford, C. 2002. Chris Crawford on Game Design. Prentice Hall, London.

CRutChfield, J.P. AND YounG, K. 1990. Computation at the onset of chaos. In Entropy, Complexity, and the Physics of Information, W. Zurek, ed., Addison-Wesley, Reading, MA., 223-269.

CsiKSZENTMIHALYI, M. 1975a. Beyond Boredom and Anxiety, Jossey-Bass, SF.

CsiksZENTMiHALYI, M. 1975b. Play and intrinsic rewards. J. Humanistic Psychology 15, 41-63.

CsiksZentmihalyi, M. AND CsiKsZentmihalyi, I. 1990. Flow: The Psychology of Optimal Experience. Harper and Row, New York.

DonKers, H.H.L.M. 2003. Nosce Hostem - Searching with opponent models. Ph.D, dissertation, IKAT/Computer Science Dept., Univ. Maastricht.

D'ANDRADE, R.G. 1995. The Development of Cognitive Anthropology. Cambridge University Press, Cambridge, MA.

DOUGLAS, Y. AND HARGADON, A. 2000. The pleasure principle: Immersion, engagement, flow. In Proceedings of the Eleventh ACM Conference on Hypertext and Hypermedia (HYPERTEXT '00, San Antonio, TX, May 30 - June 3). ACM Press, New York, 153-160.

El RhaliBI, A., HANNEGHAN, M., TANG, S., AND ENGLAND, D. 2005. Extending soft models to game design: flow, challenges and conflicts. In Proceedings of DiGRA 2005 Conference: Changing Views - Worlds in Play (British Columbia, June 16-20).

ESPERJO, R. AND HARNDEN, R., (EDS.). 1989. The Viable System Model: Interpretations and Applications of Stafford Beer's VSM. Wiley Ltd., London.

FinNERAN, C. AND ZHANG, P. 2003. A person-artefact-task (PAT) model of flow antecedents in computermediated environments. J. of Human Computer Studies 59, 475-496.

FRASCA, G. 1999. Ludology meets narratology: Similitude and differences between (video) games and narrative. http://www.ludology.org/articles/ludology.htm. Accessed May 2008.

GILLEADE, K.M. AND DIX, A. 2004. Using frustration in the design of adaptive videogames. In ACE '04: Proceedings of the 2004 ACM SIGCHI International Conference on Advances in Computer Entertainment Technology. ACM, New York, 228-232.

Groos, K. 1898. The Play of Animals. D. Appleton, New York, English translation. 
GRÜNVOGEL, S.M. 2005. Formal models and game design. Int. J. Computer Game Research 5. http://www.gamestudies.org/0501/gruenvogel/. Accessed May 2008.

HaLlam, J. AND YanNAKAKIS, G. 2007. Optimizing player satisfaction. In Proceedings of the 2007 AIIDE Workshop, Tech. Rep.WS-07-01, AAAI Press, Menlo Park, CA.

HEATON, T. 2006. A circular model of gameplay. http://gamasutra.com/features/20060223/heaton_01.shtml\#. Accessed May 2008.

Holland, J.H. 2000. Emergence: From Chaos to Order. Oxford University Press, Oxford.

HOPSON, J. 2001. Behavioural game design. http://www.gamasutra.com/features/20010427/hopson_01.htm. Accessed May 2008.

HouletTe, R. 2004. Player modelling for adaptive games. In AI Game Programming Wisdom II, S. Rabin, ed., Charles River Media, Hingham, MA.

HuIZINGA, J. 1949. Homo Ludens: A Study of the Play Element in Culture. Routledge and Paul, London.

HunicKe, R., LEBlANC, M., AND ZUBEK, R. 2004. MDA: A formal approach to game design and game research. In Proceedings of the Challenges in Game AI Workshop, 19th National Conference on Artificial Intelligence (AAAI '04, San Jose, CA), AAAI Press.

HuNT, J.M.V. 1963. Motivation inherent in information processing and action. In Motivation and Social Interaction: The Cognitive Determinants, O.J. Harvey, Ed., Ronald Press, New York, 35-94.

IsOKOSKI, P. AND MARTIN, B. 2006. Eye tracker input in first person shooter games. In Proceedings of COGAIN 2006: Gazing into the Future, 78-81.

JONES, M.G. 1998. Creating electronic learning environments: Games, flow, and the user interface. In Proceedings of Selected Research and Development Presentations at the National Convention of the Association for Educational Communications and Technology (AECT).

JÖNSSON, E. 2005. If looks could kill - An evaluation of eye tracking in computer games. Master's thesis,, Dept, of Numerical Analysis and Computer Science, Royal Institute of Technology, Stockholm, Sweden.

KaHNEmAn, D. 1973. Attention and Effort. Prentice-Hall, Englewood Cliffs, NJ.

KeIRSEY, D. 1984. Please Understand Me: Character \& Temperament Types. Prometheus Nemesis, Del Mar, CA.

Koster, R. 2005a. A Theory of Fun for Game Design. Paraglyph Press, Scottsdale, AZ.

Koster. R. 2005b. A grammar of gameplay. Presentation at the Game Developers Conference. http://www.theoryoffun.com/grammar/gdc2005.htm. Accessed May 2008.

KuCKLICH, J. 2004. Other playings - Cheating in computer games. In Proceedings of Other Players Conference (IT University of Copenhagen, Dec. 6-8.

LAZZARO, N. 2004. Why we play games: Four keys To more emotion without story. Presentation at the Game Developers Conference 2004. http://www.xeodesign.com/whyweplaygames/xeodesign whyweplaygames.pdf. Accessed May 2005.

Lewis, M.E., Mishrin, M., Bragin, E., Brown, R.M., PerT, C.B., AND PeRT, A. 1981. Opiate receptor gradients in monkey cerebral cortex: Correspondence with sensory processing hierarchies. Science 211, 1166-1169.

Lieberman, H. AND SELKER, T. 2000. Out of context: Computer systems that adapt to, and learn from, context. IBM Systems J. 39, 3 and 4.

LuDFORD, P. AND TERVEEN, L.G. 2003. Does an individual's Myers-Briggs type indicator affect task-oriented technology use? Human-Computer Interaction - Interact '03, 623-632.

MASSIMINI, F. AND CARLI, M.. 1990. Systematic assessment of flow in daily experience. In Flow: The Psychology of Optimal Experience. Harper and Row, New York.

Massimini, F., CsiKszentminalyi, M., AND Delle Fave, A. 1990. Flow and bio-cultural evolution. In Flow: The Psychology of Optimal Experience. Harper and Row, New York.

MCKENZIE, C. AND JAMES, K. 2004. Aesthetics as an aid to understanding complex systems and decision judgement in operating complex systems. In E:CO Special Double Issue 6, 1-2 (Autumn), 32-39.

MiLlER, G.A. 1956. The magical number seven, plus or minus two: Some limits on our capacity for processing information. Psychological Review 63, 81-97.

Mitchell, R.G., JR. 1990. Sociological implications of the flow experience. In Flow: The Psychology of Optimal Experience. Harper and Row, New York.

MURRAY, J.H. 1997. Hamlet on the Holodeck. Free Press, New York.

NAKATSU, R., RAUTERBERG, M., AND VORDERER, P. 2005. A new framework for entertainment computing: From passive to active experience. In Proceedings of the 4th International Conference on Entertainment Computing (CEC 2005, Sanda, Japan, Sept. 19-21).

NovaK, T.P., HOFFMAn, D.L., AND YUNG, Y.F. 2000. Measuring the customer experience in online environments: A structural modeling approach. J. Marketing Science 19, 1 (Winter), 22-44.

O'RegAN, G. 1997. Applying formal methods to model organizations and structures in the real world. Ph.D. dissertation, Dept. of Computer Science, Trinity College, Dublin.

PARLETT, D. 1999. The Oxford History of Board Games. Oxford University Press, Oxford.

ACM Computers in Entertainment, Vol. 6, No. 2, Article 20, Publication Date: July 2008. 
PEARCE, C. 1997. The Interactive Book.Macmillan, New York.

RAthunde, K. 1990. Optimal experience and the family context. In Flow: The Psychology of Optimal Experience. Harper and Row, New York.

RAUTERBERG, M. 1995. About a framework for information and information processing of learning systems. In Proceedings of the IFIP International Conference on Information System Concepts (March 28-30), 5469.

RAUTERBERG, M 1996. How to measure cognitive complexity in human-computer interaction. In Proceedings of the 13th European Meeting on Cybernetics and Systems Research (Vienna), Austrian Society for Cybernetic Studies.

RAVAJA, N., SAARI, T., LAARNI, J., KALLinEN, K., AND

SALMINEN, M. 2005. The psycho-physiology of video gaming: Phasic emotional responses to game events. In Proceedings of DiGRA 2005 Conference: Changing Views - Worlds in Play (British Columbia, June 1620).

Salen, K. And Zimmermen, E. 2003. Rules of Play: Game Design Fundamentals. MIT Press, Cambridge, MA.

Salen, K. And Zimmermen, E. (EDS). 2006. The Game Design Reader: A Rules of Play Anthology. MiT Press, Cambridge, MA.

SATO, I. 1990. Bosozkou: Flow in motorcycle gangs. In Flow: The Psychology of Optimal Experience. Harper and Row, New York.

SCHAEFFER, J. AND MATEAS, M. 2007. In Proceedings of the Third Artificial Intelligence and Interactive Digital Entertainment Conference (Stanford, CA, June 6-8), AAAI Press, Menlo Park, CA.

SHANNON, C.E. AND WEAVER, W. 1963. Mathematical Theory of Communication. University of Illinois Press.

SMOLIN, L. 2003. Loop quantum gravity. .Edge 112 (Feb).

SPRONCK, P. AND VAN DEN HERIK, J. 2005. A tutoring system for commercial games. In Proceedings of the 4th International Conference on Entertainment Computing (Sanda, Japan, Sept.), LNCS 3711, Springer, 389-400.

SPRONCK, P. 2006. Dynamic scripting. AI Game Programming Wisdom 3I, 661-675.

STEUER, J. 1995. Defining virtual reality: Dimensions determining telepresence. In Communication in the Age of Virtual Reality, 33-56.

SuITS, B. 1990. The Grasshopper: Games, Life, and Utopia. D.R. Godine, Boston, MA.

SWEETSER, P. AND WYETH, P. 2005. GameFlow: A model for evaluating player enjoyment in games. ACM Computers in Entertainment 3, 3.

WILCOX, B. 1985. Reflections on building two Go programs. ACM SIGART Bull. 94, 29-43.

Von Neumann, J. And Morgenstern, O. 1947. Theory of Games and Economic Behavior. Princeton University Press, Princeton, NJ.

Wolf, M.J.P. AND PERRON, B. (EDS.). 2003. The Video Game Theory Reader. Routledge, New York.

YANNAKAKIS, G.N., LUND, H.H., AND HALLAM, J. 2006. Modeling children's entertainment in the playware playground. In Proceedings of the IEEE Symposium on Computational Intelligence and Games (Reno, NV, May).

YANNAKAKIS, G.N. AND HALlAM, J. 2005. A generic approach for obtaining higher entertainment in predator/prey computer games. J. Game Development 1, 3, (Dec.), 23-50.

YANNAKAKIS, G.N. AND HALLAM, J. 2004. Interactive opponents generate interesting games. In Proceedings of the International Conference on Computer Games: Artificial Intelligence, Design and Education (CGAIDE, Microsoft Campus, Reading, UK, Nov.), 240-247.

YERKES, R.M. AND DODSON, J.D. 1908. The relation of strength of stimulus to rapidity of habit-formation. J.Comparative Neurology and Psychology 18, 459-482.

Received November 2007; revised March 2008; accepted April 2008 